\title{
Analisis Penghematan Daya Listrik di PT. Daikin Air Conditioning Makassar
}

\author{
Faridah \\ Jurusan Teknik Elektro, Fakultas Teknik, Universitas Islam Makassar, \\ Jl. Perintis Kemerdekaan km.9 No. 29 Makassar, Indonesia 90245 \\ email: faridah.dty@uim-makassar.ac.id
}

\begin{abstract}
Abstrak
Energi listrik sangat penting dalam industri perkantoran. Peralatan seperti pengkondisian udara (AC) merupakan peralatan yang banyak mengkonsumsi energi listrik. Hampir sekitar $60 \%$ penggunaan energi listrik digunakan untuk sistem pengkondisian udara. Hal ini merupakan suatu pemborosan energi. Tujuan Penelitian ini yaitu menghitung penggunaan daya dan efisiensi energi Audit Energi adalah teknik yang dipakai untuk menghitung besarnya konsumsi energi pada bangunan gedung dan mengenali cara-cara untuk penghematannya. Kegiatan yang dilakukan meliputi Audit Energi Awal dan Audit Energi Rinci yaitu menghitung Intensitas Konsumsi Energi (IKE) dan mencari peluang penghematan energi di bangunan tersebut.Dari hasil penelitian, didapatkan IKE pada gedung-gedung tersebut, yaitu sebesar $111,3 \mathrm{kWh} / \mathrm{m} 2 / \mathrm{Tahun}$. Hal ini mengindikasikan bahwa penggunaan energi listrik pada bangunan tersebut sudah efisien karena standard IKE pada gedung perkantoran adalah $240 \mathrm{kWh} / \mathrm{m}^{2} / \mathrm{tahun}$. Namun masih perlu diadakan beberapa perbaikan, terutama di sistem penerangan yang kualitas intensitas cahayanya masih dibawah SNI.
\end{abstract}

Kata kunci: Audit Energi, Intensitas Konsumsi,

\begin{abstract}
Electrical energy is very important in the office industry. Equipment such as air conditioning (AC) is a device that consumes a lot of electrical energy. Nearly $60 \%$ of the use of electrical energy is used for air conditioning systems. This is a waste of energy. The purpose of this study is to calculate the use of power and energy efficiency. Energy Audit is a technique used to calculate the amount of energy consumption in buildings and identify ways to save. Activities undertaken include the Initial Energy Audit and Detailed Energy Audit which is calculating the Energy Consumption Intensity (IKE) and looking for energy saving opportunities in the building. From the research results, obtained IKE in these buildings, amounting to $111.3 \mathrm{kWh} / \mathrm{m} 2$ / Year. This indicates that the use of electrical energy in the building is efficient because the IKE standard in office buildings is $240 \mathrm{kWh} / \mathrm{m}^{2} /$ year. However, some improvements still need to be made, especially in the lighting system whose quality of light intensity is still below SNI
\end{abstract}

Keywords: Energy Audit, Consumption Intensity,

\section{Pendahuluan}

Energi adalah suatu besaran yang secara konseptual dihubungkan dengan transformasi, proses atau perubahan yang terjadi. Besaran ini seringkali dikaitkan dengan perpindahan sebuah gaya atau perubahan temperature sehingga memungkinkan penentuan satuan joule (perpindahan gaya 1 Newton sejauh 1 meter), maupun kalor jenis (energi yang dibutuhkan untuk menaikkan temperatur sebesar 1 derajat per satuan massa material). Dalam keperluan praktis, energi sering kali dikaitkan 
dengan jumlah bahan bakar atau konsumsi jumlah listrik. (Badan Koordinasi Energi Nasional, 1983).

Pada audit di Gedung PT. Daikin Air Conditioning terlihat bahwa biaya operasional energi listrik terlihat yang paling dominan. Oleh sebab itu perlu diadakan penghematan energi untuk menekan pemakaian energi listrik di PT. Daikin Air Conditioning. untuk itu dilakukan audit energi untuk menghitung tingkat pemakaian listrik dan menekan pemakaian listrik di perusahaan tersebut dengan cara menganalisis pemakaian komsumsi tenaga listrik dimana pemakaian listrik yg terlalu tinggi di kurangi dengan mengunakan suatu alat yg dapat menghemat energi listrik di perusahaan tersebut.

Berdasarkan latar belakang dan permasalahan Bagaimana menghitung penggunaan daya pada PT. Daikin Air Conditioning Makassar dan Bagaimana penerapan efisiensi energi pada PT. Daikin Air Conditioning Makassar. Agar pada PT. Daikin Air Conditioning dapat meningkatkan mutu dan efisiensi dalam menggunakan energi listrik.

\section{Metode}

Alat, Bahan dan Metode :

Dalam melakukan penelitian ini, kami menggunakan alat dan bahan :

\section{Termometer}

2. Tang Ampere

3. Timer listrik

4. Kontaktor Listrik

5. Relay

Metode pengumpulan data ialah cara atau strategi yang ditempuh untuk mengambil data dari varibel penelitian tersebut. Metode yang digunakan dalam penelitian ini adalah metode pengumpulan data observasi secara langsung di lapangan.

Variabel penelitian meliputi jumlah pemakaian energi berdasarkan audit energi awal dan audit energi rinci serta peluang penghematan berdasarkan kondisi lapangan.

\section{Hasil dan Pembahasan}

\section{Audit Energi Awal}

Dalam perhitungan audit energi awal ini, akan dicari nilai IKE (Intensitas Konsumsi Energi) pada kantor PT. Daikin Airconditioning cabang Makassar, dengan memanfaatkan data historis energi (data yang diperoleh tanpa hasil pengukuran) serta data - data bangunan yang telah kami data luasan area kotor serta luasan area kantor yang dikondisikan. Dalam analisisnya, akan ditampilkan gambaran siklus pemanfaatan energi yang terjadi pada kantor PT. Daikin Airconditioning cabang Makassar serta jumlah 
pemakain energy listrik selama setahun. Selain itu, juga akan dianalisis apakah IKE pada kantor PT. Daikin Airconditioning cabang Makassar telah sesuai dengan target atau standar IKE untuk perkantoran di Indonesia berdasarkan jumlah pembayaran rekening listrik dan jumlah pemakain KWh yang diambil dari data histori pembayaran PT. Daikin Airconditioning cabang Makassar selama setahun terakhir. Apabila standar IKE belum terlaksa maka pelaksanaan audit energi akan dilanjutkan ke tahap selanjutnya yaitu audit energi rinci. (Wahid, A., Junaidi, M.I. Arsyad, 2014)

\section{Denah Tampak Gedung dan Jaringan Gedung}

Denah gedung secara detail bisa dilihat di lampiran. Untuk luasan area kantor PT. Daikin Airconditioning cabang Makassar, memiliki luas tanah tempat usaha $225.6 \mathrm{~m}^{2}$ terdiri dari lantai 1, 2 dan 3 dan komposisi luas bangunan kantor PT. Daikin Airconditioning cabang Makassar sebagai berikut.

Tabel 1. Komposisi luas bangunan kantor PT. Daikin Airconditioning cabang Makassar

\begin{tabular}{|c|c|c|c|}
\hline No & Lantai & Area & $\begin{array}{c}\text { Luas } \\
\text { Area }\left(\mathrm{m}^{2}\right)\end{array}$ \\
\hline 1 & \multirow{4}{*}{1} & Teras depan & 6,4 \\
\hline 2 & & Show room & 31,7 \\
\hline 3 & & Workshop & 17,4 \\
\hline 4 & & Toilet & 2,1 \\
\hline 5 & \multirow{4}{*}{2} & Office & 31,7 \\
\hline 6 & & Meeting room & 17,4 \\
\hline 7 & & Pantry & 32,5 \\
\hline 8 & & Toilet & 2,1 \\
\hline 9 & \multirow{4}{*}{3} & R. Spare part & 50 \\
\hline 10 & & R. Penyimpanan & 25 \\
\hline 11 & & Teras depan & 3 \\
\hline & & Toilet & 2,1 \\
\hline & & TOTAL & 225,6 \\
\hline
\end{tabular}
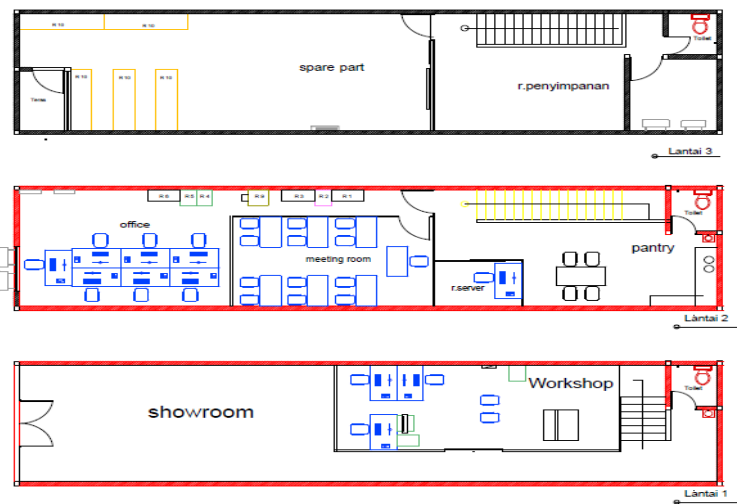

Gambar 2. Denah Tampak Atas Kantor PT. Daikin Airconditioning cabang Makassar 


\section{Sistem Distribusi Energi}

PT. Daikin Airconditioning cabang Makassar menggunakan sumber energi listrik yang disupply dari PLN dengan 16.500 Va yang berada pada golongan tarif Bisnis B2/Tr. Adapun pendistribusian energi listrik pada kantor PT. Daikin Airconditioning cabang Makassar adalah sebagai berikut : Suplai listrik dari PLN yang merupakan listrik tegangan kabel rendah SKTR yang terhubung dengan KWh meter dan siap didistribusikan ke panel distribution box (PDB).

\section{Kualitas Daya}

Berikut ini adalah data hasil pengukuran tegangan dan arus pada panel induk di kantor PT. Daikin Airconditioning cabang Makassar :

Tabel 1. Hasil pengukuran tegangan dan arus pada panel induk

\begin{tabular}{|c|c|c|}
\hline Phase & $\begin{array}{c}\text { Tegangan (V) } \\
\text { Phase }-\mathrm{N}\end{array}$ & Arus (A) \\
\hline R & 215 & 18,84 \\
\hline S & 216 & 12,5 \\
\hline T & 221 & 7,3 \\
\hline N & - & 11,8 \\
\hline
\end{tabular}

\section{Data Konsumsi Energi}

Berikut ini adalah data-data konsumsi energi serta alokasinya di kantor PT. Daikin Airconditioning cabang Makassar selama satu tahun : Periode bulan Agust 2016 - Juli 2017.

Tabel 3. Data Rekening Konsumsi Energi Listrik selama 1 tahun

\begin{tabular}{|c|c|c|}
\hline Bulan & $\begin{array}{c}\text { Total } \\
\text { KWh }\end{array}$ & $\begin{array}{c}\text { Pembayaran } \\
(\mathrm{Rp})\end{array}$ \\
\hline Agus-2016 & 2,907 & $4,500,000$ \\
\hline Sep-2016 & 2,261 & $3,500,000$ \\
\hline Okt-2016 & 1,518 & $2,351,000$ \\
\hline Nov-2016 & 1,680 & $2,601,000$ \\
\hline Des-2016 & 1,634 & $2,530,000$ \\
\hline Jan-2017 & 2,584 & $4,000,000$ \\
\hline Feb-2017 & 1,485 & $2,300,000$ \\
\hline Mar-2017 & 1,938 & $3,000,000$ \\
\hline Apr-2017 & 2,261 & $3,500,000$ \\
\hline Mey-2017 & 2,261 & $3,500,000$ \\
\hline Jun-2017 & 2,261 & $3,500,000$ \\
\hline Juli-2017 & 1,938 & $3,000,000$ \\
\hline Total & 24,782 & $38,282,000$ \\
\hline
\end{tabular}




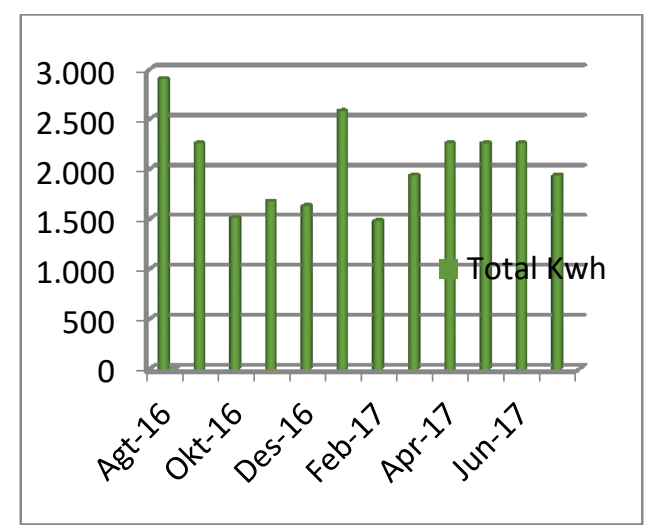

Gambar 3. Grafik Pemakaian Energi Listrik Kantor PT. Daikin Airconditioning cabang Makassar

\section{Analisis Tingkat Kuat Pencahayaan}

Dari hasil penelitian diketahui bahwa sebagian besar aktifitas di PT. Daikin Airconditioning cabang Makassar dilakukan pada siang hari. Dan ruang-ruangan kantor PT. Daikin Airconditioning cabang Makassar menggunakan penerangan lampu. Hanya di tempat tempat tertentu mengunakan penerangan alami.

Perbandingan tingkat kuat penerangan hasil pengukuran dengan standar yang sudah ditetapkan dalam SNI 03-6197-2000 untuk beberapa sampel ruangan dapat dilihat pada label berikut :

Tabel 4 Hasil Pengukuran Kuat Penerangan Cahaya

\begin{tabular}{|c|l|c|c|c|}
\hline \multirow{2}{*}{ No } & \multirow{2}{*}{ Nama Ruangan } & \multicolumn{2}{|c|}{ LUX } & \multirow{2}{*}{$\begin{array}{c}\text { Komparasi } \\
\text { dengan SNI }\end{array}$} \\
\cline { 3 - 4 } & & Terukur & $\begin{array}{c}\text { Standar SNI } \\
03-6575-2001\end{array}$ & Melebihi SNI \\
\hline 1 & Teras depan & 62 & 50 & Dibawah SNI \\
\hline 2 & Show room & 230 & 500 & Dibawah SNI \\
\hline 3 & Workshop & 210 & 500 & Dibawah SNI \\
\hline 4 & Toilet & 139 & 250 & Dibawah SNI \\
\hline 5 & Office & 170 & 350 & Dibawah SNI \\
\hline 6 & Meeting room & 200 & 300 & Dibawah SNI \\
\hline 7 & R. server & 200 & 300 & Dibawah SNI \\
\hline 8 & Pantry & 174 & 300 & Dibawah SNI \\
\hline 9 & Toilet & 139 & 250 & Dibawah SNI \\
\hline 10 & R. Spare part & 200 & 300 & Sesuai SNI \\
\hline 11 & R. Penyimpanan & 150 & 150 & Melebihi SNI \\
\hline 12 & Teras depan & 60 & 50 & Dibawah SNI \\
\hline 13 & Toilet & 139 & 250 & \\
\hline
\end{tabular}

Dari tabel 4 diketahui bahwa hampir semua ruangan yang ada dikantor PT. Daikin Airconditioning cabang Makassar, tingkat kuat penerangannya berada dibawah standar yang telah ditetapkan dalam SNI 03-6575.2001

Pemakain listrik pada peralatan kantor 
Tabel 5. Pemakain listrik pada peralatan kantor lainnya

\begin{tabular}{|c|l|c|c|c|c|c|}
\hline No & Nama Peralatan & $\begin{array}{c}\text { Daya } \\
\text { (Watt) }\end{array}$ & QTY & $\begin{array}{c}\text { Jam } \\
\text { Nyala }\end{array}$ & $\begin{array}{c}\text { Jumlah Hari } \\
\text { /bulan }\end{array}$ & $\begin{array}{c}\text { Komsumsi } \\
\text { (kWh) }\end{array}$ \\
\hline 1 & TV & 335 & 1 & 3 & 22 & 1,005 \\
\hline 2 & PC & 160 & 14 & 9 & 22 & 20,16 \\
\hline 3 & EXHAUST & 65 & 3 & 24 & 30 & 4,68 \\
\hline 4 & PRINTER & 35 & 3 & 2 & 22 & 0,21 \\
\hline 5 & M. FOTO COPY & 1760 & 1 & 3 & 22 & 5,28 \\
\hline 6 & PROJECTOR & 264 & 1 & 2 & 22 & 0,528 \\
\hline 7 & DISPENSER & 350 & 1 & 12 & 22 & 4,2 \\
\hline 8 & DISPENSER & 390 & 1 & 12 & 22 & 4,68 \\
\hline & Rata - rata hari kerja/ bulan (hari) \\
\hline & \multicolumn{6}{l}{ Total Komsumsi per Hari(kWh) } \\
\hline
\end{tabular}

Berdasarkan data hasil analisa dan perhitungan pemakaian energy listrik PT. Daikin Airconditioning cabang Makassar diperoleh komsumsi energy selama 1 tahun terakhir sebagai berikut:

1. Sytem pencahayaan $\quad: 1.256 .90 \mathrm{kWh} /$ Tahun.

2. Sytem tata udara : $12.777 .98 \mathrm{kWh} /$ Tahun.

3. Peralatan kantor Lainnya : 11.245.07kWh/Tahun.

Berdasarkan data tersebut dapat digambarkan dalam bentuk diagram pie chard dan diperoleh hasil yang ditunjukkan pada gambar 4 .

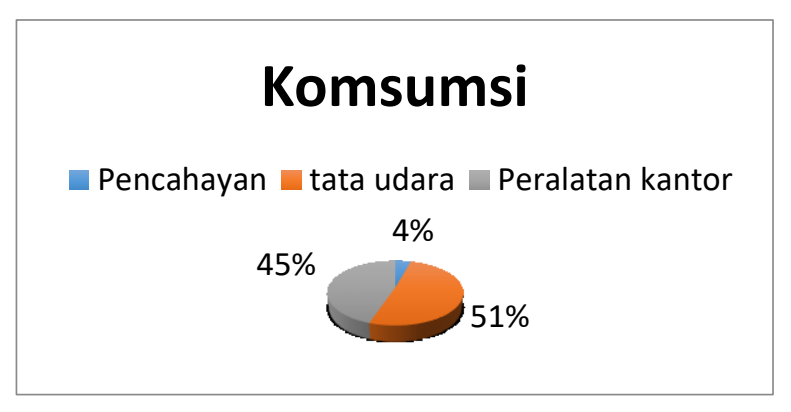

Gambar 4.Presentase komsumsi energi listrik dalam Diagram pie

\section{Intensitas Komsumsi IKE (IKE)}

Dari data konsumsi energi dan data luasan bangunan, maka dapat dihitung besarnya intensitas konsumsi energi (IKE) Kantor PT. Daikin Airconditioning cabang Makassar selama satu tahun dengan periode bulan Agustus 2016 sampai dengan Juli 2017. Adapun perhitungannya sebagai berikut; 


$$
\begin{gathered}
\text { IKETotal }=\frac{\text { Total } \mathrm{kWh}}{\text { Luas Bangunan }} \ldots \ldots \ldots \ldots \ldots \\
\text { IKETotal }=\frac{24728 \mathrm{kWh}}{421,24 \mathrm{~m}^{2}} \\
\text { IKETotal }=58,70 \mathrm{kWh} / \mathrm{m}^{2} / \text { Tahun }
\end{gathered}
$$

Dengan cara perhitungan yang sama dapat dilakukan perhitungan untuk seluruh data dan menghasilkan data sebagai berikut:

Tabel 6. Perhitungan Intensitas Komsumsi IKE (IKE)

\begin{tabular}{|c|c|c|c|c|}
\hline No & Bulan & $\begin{array}{c}\text { Luas } \\
\text { Bangunan(M2) }\end{array}$ & kWh/Bulan & $\begin{array}{c}\text { IKE } \\
\text { (kWh/M2/BIn) }\end{array}$ \\
\hline 1 & Agu-16 & 421,24 & 2.907 & 6,90 \\
\hline 2 & Sep-16 & 421,24 & 2.261 & 5,37 \\
\hline 3 & Okt-16 & 421,24 & 1.518 & 3,60 \\
\hline 4 & Nov-16 & 421,24 & 1.680 & 3,99 \\
\hline 5 & Des-16 & 421,24 & 1.634 & 3,88 \\
\hline 6 & Jan-17 & 421,24 & 2.584 & 6,13 \\
\hline 7 & Feb-17 & 421,24 & 1.485 & 3,53 \\
\hline 8 & Mar-17 & 421,24 & 1.938 & 4,60 \\
\hline 9 & Apr-17 & 421,24 & 2.261 & 5,37 \\
\hline 10 & Mey-2017 & 421,24 & 2.261 & 5,37 \\
\hline 11 & Jun-17 & 421,24 & 2.261 & 5,37 \\
\hline 12 & Jul-17 & 421,24 & 1.938 & 4,60 \\
\hline \multicolumn{4}{|l|}{ Total } \\
\hline \multicolumn{4}{|l|}{ Rata pemakain / bulan } \\
\hline \multicolumn{4}{|l}{ Rata - rata IKE Bulanan } \\
\hline \multicolumn{2}{|l}{ Total IKE Tahunan } & & 58,70 \\
\hline
\end{tabular}

Dilihat dari nilai target IKE yang digunakan yaitu standar IKE Asean Usaid tahun 1992 dimana untuk klasifikasi perkantoran yaitu sebesar $240 \mathrm{kWh} / \mathrm{m} 2$ /Tahun, maka dapat dikatakan dari data perhitungan IKE listrik per satuan luas bangunan kantor PT. Daikin Airconditioning cabang Makassar berdasarkan data konsumsi energi dari rekening pembayaran listrik pada periode bulan Agustus 2016 sampai dengan juli 2017 sebesar 4,89 kWh/m2/bulan atau 109,6 kWh/m2 /Tahun. Angka ini masih berada dibawah batas standar (target IKE) yang ditentukan sehingga bisa dikatakan bahwa nilai IKE masih efisien.

Apabila ditinjau dari segi kelayakan dan kenyaman kerja masih berada di bawah Standar Nasional Indonesia (SNI) yang telah di tentukan terutama pada aspek penerangan. 


\section{Kesimpulan}

Dari uraian data hasil penelitian serta analisis hasil perhitungan harmonisasi tegangan dan arus listrik pada PT. Daikin Indonesia ,maka dapat di simpulkan:

1. Penggunaan daya di PT. Daikin adalah sebagai berikut :

- Sistem tata udara : Dengan standar yang ditetapkan SNI 0365722001 mngenai kenyamanan pengkondisian udara maka suhu dan kelembaban udara disetiap ruangan kantor PT. Daikin Airconditioning cabang Makassar telah memenuhi standart. Dan untuk konsumsi energi listrik per tahun dalam system Tata Udara mencapai $12.777 .98 \mathrm{kWh} / \mathrm{Tahun}$

- Sistem Pencahayaan : Dapat diketahui bahwa rata - rata konsumsi energi listrik per bulan untuk sistem pencahayaan yaitu $104.74 \mathrm{kWh} / \mathrm{bulan}$ dan pertahun mencapai : $1.256 .90 \mathrm{kWh} / \mathrm{Tahun}$

- Sistem listrik pada peralatan kantor : komsumsi pemakain listrik pada peralatan kantor Sebesar 937,09 kWh/Bulan dan untuk pertahunya mencapai 11.245.07 $\mathrm{kWh} /$ Tahun

2. Penerapan efisiensi daya Di PT. Daikin

Dengan menerapkan suatu sistem penghematan dengan menggunakan sistem kontrol saklar otomatis dapat menghemat pemakain litrik perharinya 6,78 Kwh

- Komsumsi penghematan perbulan : 160,07 Kwh

- Komsumsi penghematan Pertahun : 1.653,74 Kwh

\section{Daftar Pustaka}

Badan Koordinasi Energi Nasional, 1983 Buku pedoman tentang Cara-cara melaksanakan Konversi Energi dan Pengawasannya. Jakarta Departemen Pertambangan dan Energi

Zuhal, 1995, Dasar Teknik Tenaga Listrik dan Elektronika Daya , Jakarta Gramedia Pustaka Utama

Prasetya, Y., 2014, Analisis Peningkatan Efisiensi Penggunaan Energi Listrik pada Sistem Pencahayaan dan Air Conditioning (AC) di Gedung Perpustakaan Umum dan Arsip Daerah Kota Malang, Jurnal Skripsi Konsentrasi Teknik Energi Listrik, Universitas Brawijaya, Malang.

Wahid, A., Junaidi, M.I. Arsyad, 2014, Analisis Kapasitas dan Kebutuhan Daya Listrik untuk Menghemat Penggunaan Energi Listrik di fakultas Teknik Universitas Tanjungpura, Universitas Tanjungpura, Pontianak. 